\title{
Deixando o Preconceito de Lado e Entendendo o Behaviorismo Radical'
}

Putting prejudice aside and understanding the radical behaviorism

Resumo: O behaviorismo radical de Skinner é, muitas vezes, criticado de forma indevida e até preconceituosa. Muitas dessas críticas, na verdade, são críticas à psicologia de Watson e não ao behaviorismo radical. O entendimento das diferenças entre os modos idealista e materialista de pensar ajuda a esclarecer a maneira de estudar e compreender o comportamento para o behaviorismo radical, bem como a sua posição antimentalista. O estudo da história da evolução do behaviorismo é necessário para possibilitar o entendimento das diferenças entre o behaviorismo metodológico de Watson e o behaviorismo radical de Skinner, bem como das suas respectivas contribuições para a Psicologia.

Palavras-Chave: Behaviorismo metodológico, behaviorismo radical, diferenças.

Abstract: Skinner's radical behaviorism is many times criticized in an inappropriate and prejudiced way. Actually, many of these critics fit Watson's psychology, not radical behaviorism. Understanding the differences between the idealist and the materialist way of thinking helps to clear the way of studying and understanding the behavior for radical behaviorism, as well as its not mentalist position. The study of the historical evolution of behaviorism is necessary in order to understand the differences between methodological and radical behaviorism as well as their contributions to Psychology.

Key Words: Methodological behaviorism, radical behaviorism, differences.

\section{Rodrigo \\ Pinto Guimarães \\ Psicólogo, formado pela Universidade \\ Federal da Bahia (UFBA). \\ Mestrando em Análise \\ do Comportamento pela Pontifícia Universidade Católica de São Paulo (PUC - SP).}

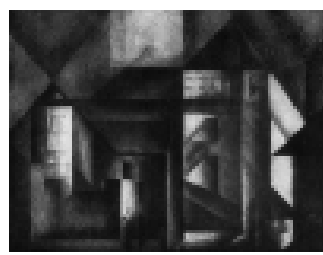

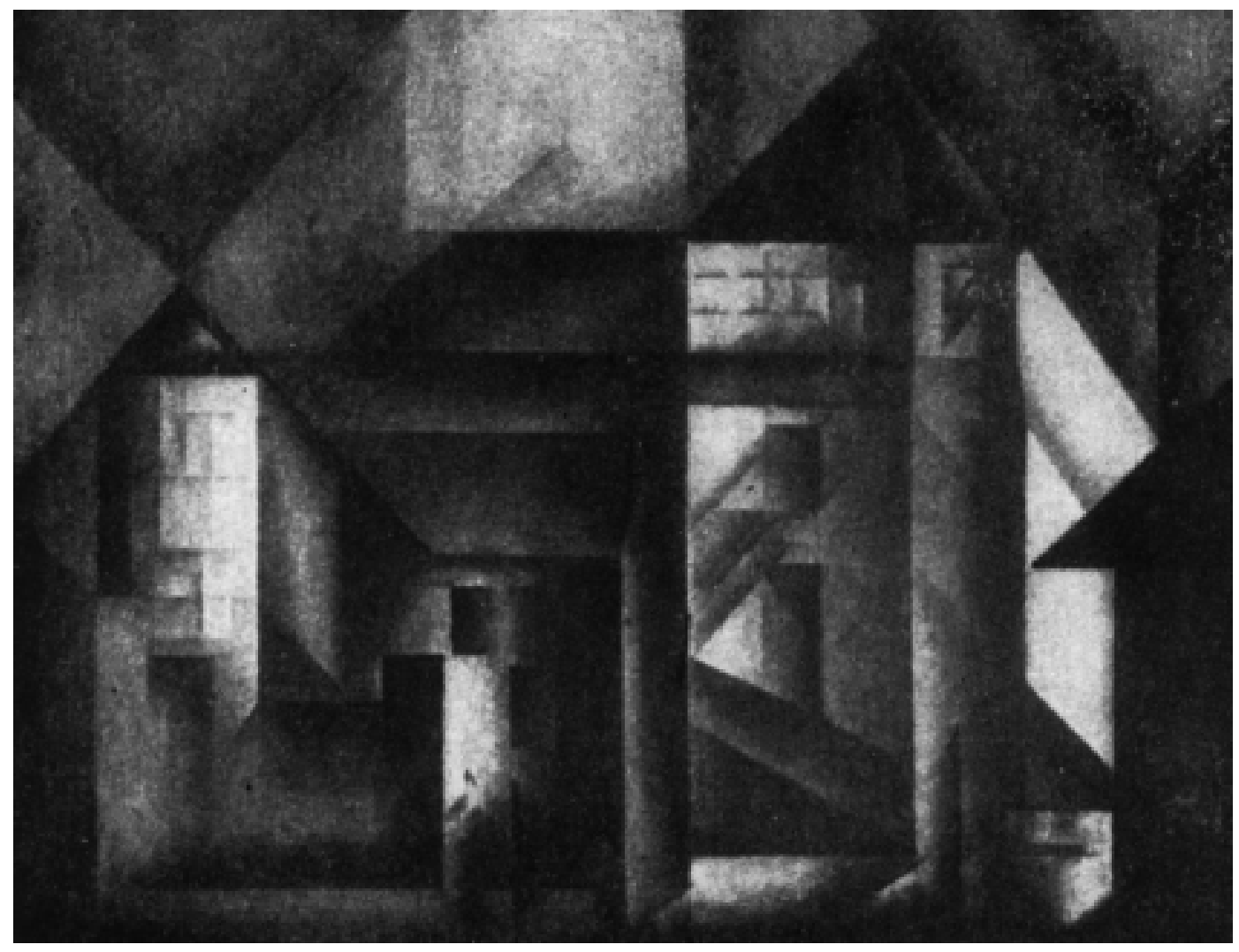

\section{Idealismo e Materialismo}

Na cultura ocidental, é bem difundida a maneira idealista de pensar. Ao seguir uma concepção idealista da realidade, freqüentemente as pessoas acabam por fazer atribuições causais - relação de causa e efeito entre eventos - sem que haja de fato as causas dos fenômenos comportamentais estão nas idéias, ou seja, de forma geral, o uma relação funcional entre eles. Para o idealismo, 
comportamento se baseia em causas imaginárias e constructos hipotéticos ${ }^{2}$, distanciando-se da dimensão física e natural do homem. As atribuições causais dos povos primitivos são bons exemplos de concepções idealistas, para as quais a causa das doenças, da pouca produtividade nas colheitas, das pragas, pestes ou de qualquer tipo de infortúnio que pudesse ocorrer era determinada pelo Deus Sol, pela Lua, enfim, por forças cósmicas não alcançadas pelo homem. Nesse sentido, nada se podia fazer para evitar tais infortúnios, uma vez que o homem estava à mercê dessas forças. Esse tipo de concepção é, mais especificamente, chamada de idealismo objetivo, no qual as causas dos fenômenos estão fora do organismo. Há, no entanto, o idealismo subjetivo, onde as causas dos fenômenos são constructos hipotéticos e imaginários, mas que se situam dentro do indivíduo e não fora dele (Camillo, 1988). Nessa concepção idealista subjetiva, encaixam-se a psicanálise e o cognitivismo, para as quais, em geral, as causas dos comportamentos estão no inconsciente ou nos processos mentais, respectivamente. Parece existir uma circularidade muito grande nessa argumentação, pois, ao mesmo tempo em que o comportamento é causado pelo inconsciente ou pelos ditos processos mentais, a única prova de existência dos mesmos é o próprio comportamento (Matos, 1993).

Para o behaviorismo radical, todos os fenômenos estão em uma dimensão natural, saindo-se, então, de um dualismo mente $\mathrm{x}$ corpo, no qual um conceito metafísico (mente, inconsciente, ego etc.) é responsável pelo comportamento, para uma concepção monista de homem. Sendo assim, idéia não gera comportamento, pois tanto os eventos comportamentais quanto as idéias estão em uma mesma dimensão natural. Desse modo, as explicações sobre os fenômenos comportamentais devem ser feitas através de causas naturais, reais e passíveis de observação, ainda que só do próprio indivíduo que observa.

\section{Causa do Comportamento}

Se uma idéia não causa um comportamento, o que o causa? Como explicar a raiva, a paixão, o ódio?... Para o behaviorismo radical, a paixão, a raiva, o ódio etc., são os próprios comportamentos. Tal explicação tende a ser preliminarmente rejeitada e descartada sem o devido aprofundamento, uma vez que ela é bem diferente e até destoante da que se aprende na cultura mentalista, para a qual a emoção causa o comportamento. Para melhor esclarecimento, será feita uma tentativa de explicar um sistema causal anti-mentalista como o do behaviorismo radical. Para isso, é necessário esclarecer a questão abaixo: Suponha-se que um sujeito qualquer apresente alucinações auditivas, visuais, delírios e que esteja incapacitado para o convívio social, por ser muito agressivo e se sentir ameaçado por quase todo mundo devido às suas idéias delirantes. Diante de tais sintomas comportamentais, seria possível dizer que o sujeito é psicótico. Pergunta-se, então: o referido indivíduo é psicótico porque tem alucinações e idéias delirantes, ou tem idéias delirantes e alucinações porque é psicótico? Notase, aí, que a escolha de qualquer uma dessas alternativas remeterá a uma explicação circular sem fim.

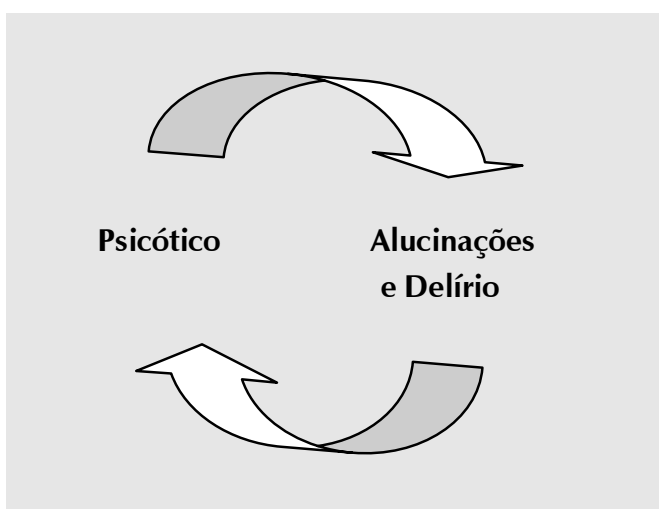

Um outro exemplo, mais perto da realidade: imagine que você esteja dirigindo seu carro novo, tranqüilamente, quando um motorista embriagado acaba batendo nele, deixando-o extremamente irritado e nervoso. Suponha que, nessa situação, você saia do carro e dê um soco no rosto do referido motorista. Pergunta-se, então: você bateu no motorista porque estava com raiva dele? Se você responder positivamente a essa pergunta, estará incorrendo em erro, pois na verdade, você bateu nele porque ele bateu no seu carro novo, um estímulo ambiental externo ao indivíduo, e não porque uma "entidade" chamada raiva fez você bater no motorista. Em outras palavras, o comportamento publicamente observável de dar um soco em alguém ou de gritar, juntamente com alterações corporais em todos os níveis hormonais, musculares, gástricos etc. - é a raiva. Essa problemática na atribuição causal aconteceu quando o homem começou a adquirir a fala. Pensando na evolução filogenética do homem, chega-se à conclusão de que em algum momento o homem, enquanto espécie, começou a desenvolver o comportamento verbal. Pois bem, nesse processo de desenvolvimento do comportamento verbal, o homem nomeou certos tipos de comportamentos, como, por exemplo, o comportamento de comer desesperadamente, sem mastigar direito a comida, sem lavá-la nem preparála adequadamente etc., dando-lhe o nome de fome, ou seja, construiu-se um símbolo, nesse caso a palavra FOME, para representar tais comportamentos na fala. Portanto, quando alguém
1 Trabalho elaborado na graduação com a finalidade de falar sobre características do behaviorismo radical na tentativa de minimizar críticas que, na visão do autor; são preconceituosas e infundadas sobre essa abordagem. Não pretende, portanto, explicar exaustivamente nem encerrar discussóes sobre nenhum dos pontos levantados.

2 Constructos são conceitos especiais e complexos que representam algum tipo de relação entre eventos ou objetos Marx e Hillix, 1973). Segundo MacCorquodale e Meehl (Apud Marx e Hillix, 1973), constructos hipotéticos apresentam um problema de excesso de significado, ou seja, eles possuem significados que não são justificáveis por sua 


\section{É necessário tornar claro que o \\ behoviorismo radical não nega sentimentos, \\ emocões ou a importância da significação de uma experiência para um indivíduo, \\ simplesmente não toma emoções, sentimentos, nem a significação deles como causa dos comportamentos, e, sim, como maneiras de se comportar.}

definição operacional. 3 Esse ponto deixa evidenciado que, para o autor; o behaviorismo radical não é determinista, como muitas pessoas afirmam. Alguns autores (Matos, 1993 e Tourinho, 2001) usam o termo "determinismo probabilistico" ao invés de "contingências de controle", porém a própria noção de probabilidade vai contra a noção de determinismo. Se algo é provável, não é determinado. $O$ uso do termo "contingêncic de controle" pode mostrar isso, pois a noção de contingência de algo que pode ou não ocorrer, não havendo nenhum tipo de certeza, nem de garantia que comportamento ocorra. Dessa maneira, não há determinismo. se comporta dessa maneira, diz-se que esse alguém "está com fome". O problema, então, surgiu quando a ordem dos fatos foi invertida e o homem começou a usar as palavras como causa desses mesmos comportamentos. Dito de outra maneira, não se come desesperadamente porque se está com fome, mas isso é a própria fome. Não se bate em ninguém porque se está com raiva, isso é a própria raiva. $O$ indivíduo come porque ficou privado de alimento por tempo suficiente para causar um desequilíbrio na homeostase do seu organismo. Um sujeito bate em alguém porque houve algum acontecimento externo que o desagradou, e não porque exista nele uma entidade chamada raiva que o tenha impulsionado à ação, ao comportamento, mesmo porque a raiva, o ódio e a fome são apenas palavras, nada mais.

É necessário tornar claro que o behaviorismo radical não nega sentimentos, emoções ou a importância da significação de uma experiência para um indivíduo, simplesmente não toma emoções, sentimentos, nem a significação deles como causa dos comportamentos, e, sim, como maneiras de se comportar.

"A análise do comportamento edifica-se como uma modalidade de discurso psicológico que é crítico dessa visão de homem e da correspondente sobrevalorização do que ocorre privadamente ao indivíduo. Não porque ignora a chamada "experiência subjetiva", ou deixa de reconhecê-la como constitutiva de instâncias do fenômeno comportamental, mas porque não atribui a esses eventos uma centralidade na explicação do comportamento humano; diferente disso, busca na relação do homem com o mundo uma explicação tanto para sua experiência subjetiva quanto para seu comportamento publicamente partilhado" (Tourinho, 2001).

\section{Uma Questão de Vocabulário.}

Outro grande problema que não ajuda a compreender a análise em questão é o vocabulário mentalista, que leva as pessoas a pensarem de uma maneira mentalista sobre a realidade (Matos, 1993). Skinner, em seu livro Sobre o Behaviorismo, fala sobre esse assunto. Certos substantivos deveriam ser verbos. Note que, no parágrafo acima, a expressão "está com fome" foi colocada entre aspas, pois o correto seria que a palavra fome fosse um verbo, ou seja, eu fomeio, ao invés de "eu tenho fome", porque quando se diz "estou com fome", pode-se pensar que existe uma entidade chamada fome que se apossa do indivíduo e o leva ao comportamento de comer, mas a palavra fome é simplesmente uma forma de comportamento. Da mesma maneira, ninguém sente ou tem raiva, mas raiveia, uma vez que raiva é apenas e tão somente uma maneira de se comportar. Esses são apenas alguns dentre os vários exemplos referentes à linguagem.

É importante ter ficado claro que, para o behaviorismo radical, a causa do comportamento não está dentro do indivíduo, em alguma instância causadora ou mediadora do comportamento, mas, sim, no ambiente, mesmo que seja o ambiente interno (o próprio organismo), uma vez que o organismo é considerado parte do ambiente. O comportamento, nessa abordagem, é a relação do organismo com o ambiente, levando em consideração a estrutura genética e a história de vida do referido organismo. Nela, migra-se de um determinismo unidirecional e mecanicista (inconsciente $\rightarrow$ comportamento ou processos mentais $\rightarrow$ comportamento) para uma contingência de controle, na qual a estrutura genética, a história de vida e os estímulos ambientais presentes, em uma gama de relações entre si, condicionam o comportamento do organismo $^{3}$. Foi usada a palavra organismo, mas poderia ter sido a palavra pessoa, ser humano etc. Essa colocação é pertinente, pois uma das críticas feitas ao behaviorismo radical, por algumas pessoas, é que o vocabulário behaviorista é muito "pesado" e "desumano", tirando o homem do seu lugar de "Ser Humano", e tratando-o como um "animal". Surge, então, uma questão: será que os seres humanos, em algum momento, deixaram de ser animais? Pelo visto, não. A capacidade de construir conhecimento (um dos aspectos que diferencia o homem dos outros animais), não nega nem afasta a condição animal do homem. Portanto, essa parece ser uma mera questão de eufemismo. Qual a diferença prática entre os seguintes comentários? "Oh! Os aplausos que recebo dos meus alunos, quando termino uma palestra, me nutrem" e "Oh! Os aplausos que recebo dos meus alunos, quando termino uma palestra, são reforçadores"? É claro que, na clínica, na relação com os pacientes, deve-se buscar maneiras de comunicação sem se usar um linguajar técnico, nem tão pouco um linguajar que pareça muito seco e/ou ríspido. Addis (1995), em seu artigo, apresenta um exemplo interessante sobre essa questão quando fala sobre a frustração de um estudante que perguntava: "como posso explicar para uma esposa que seu marido não tem comportamentos facilitadores de intimidade e que seus tatos são, na verdade, mandos disfarçados"?

\section{Evolução do Behaviorismo}

Para continuar falando sobre a causa do comportamento no behaviorismo radical de Skinner, é necessário comentar sobre o behaviorismo metodológico e mediacional, para que seja possível entender que muitas das críticas 
feitas a Skinner, são críticas, na verdade, ao behaviorismo de Watson, também conhecido como behaviorismo metodológico.

Watson foi influenciado por Pavlov (Matos, 1993) e criou um paradigma de comportamento, $S \rightarrow R$, conhecido como estímulo-resposta. É claro que esse paradigma explica apenas uma parcela muito pequena dos comportamentos humanos, os chamados comportamentos reflexos ou respondentes e os comportamentos reflexos ou respondentes condicionados. Comportamentos reflexos ou respondentes são aqueles em que um estímulo está diretamente relacionado a uma determinada resposta do organismo, ou seja, determinado estímulo elicia determinada resposta em um organismo. Esse tipo de estímulo é chamado de estímulo incondicionado. Por exemplo, quando um sujeito levanta a perna imediatamente após o médico ter batido com um martelo em seu joelho, ele está se comportando dentro desse modelo $S \rightarrow R$, e esse comportamento de levantar a perna é um comportamento reflexo. O comportamento reflexo condicionado, por sua vez, é um pouco diferente, pois necessita de aprendizagem, uma vez que nesse tipo de comportamento um estímulo neutro será pareado com um estímulo incondicionado para que, futuramente, esse estímulo neutro seja capaz de produzir no organismo a mesma resposta que o estímulo incondicionado, passando, então, a ser chamado de estímulo condicionado. Como exemplo, há a famosa experiência de Pavlov com cães, onde ele pareia o som de uma campainha com a apresentação de comida e, após algum tempo, o cachorro saliva apenas com a apresentação do som da campainha (estímulo neutro que se tornou condicionado à apresentação de comida), sem precisar da apresentação da própria comida (estímulo incondicionado). Sendo assim, o behaviorismo de Watson ficou conhecido como psicologia estímulo-resposta, e não o behaviorismo radical de Skinner.

Watson rejeitava a introspecção como meio para se obter informações e conhecimento. Adotou como critério o observável consensual, e o que estivesse fora desse critério não poderia ser estudado. Watson não negava a existência da mente ou de processos cognitivos, mas afastava-se deles, pois não havia como estudá-los, uma vez que são eventos inacessíveis à observação. Portanto, não poderiam ser tomados como ponto de partida para o estudo do comportamento, nem como causa dele (Matos, 1993). Observa-se que a postura desse paradigma é dualista, pois a mente e os processos mentais estão em uma dimensão e os comportamentos em outra; mecanicista porque transmite uma idéia causal de encadeamento unidirecional, sequencial e linear; determinista, pois para toda resposta existiria um estímulo eliciador específico (assim como na física newtoniana); reducionista, pois reduziu e igualou o homem a uma máquina; também foi influenciado pelo positivismo lógico.

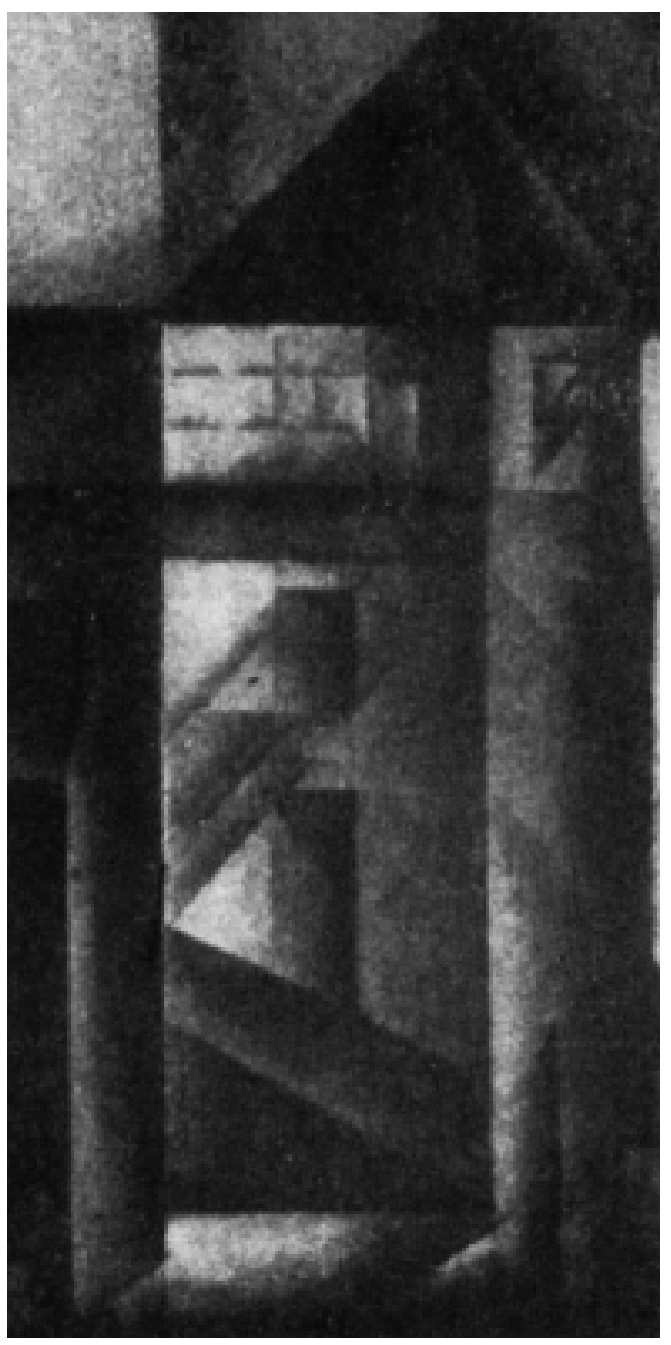

A análise do comportamento edifica-se como uma modalidade de discurso psicológico que é crítico dessa visão de homem e da correspondente sobrevalorização do que ocorre privadamente ao indivíduo. Não porque ignora a chamada "experiência subjetiva", ou deixa de reconhecê-la como constitutiva de instâncias do fenômeno comportamental, mas porque não atribui a esses eventos uma centralidade na explicação do comportamento humano; diferente disso, busca na relação do homem com o mundo uma explicação tanto para sua experiência subjetiva quanto para seu comportamento publicamente partilhado"

Tourinho
Posteriormente, alguns behavioristas começaram a rejeitar esse modelo e assumiram uma outra postura, na qual o ambiente perdia o seu lugar primordial na causação do comportamento para cedê-lo de volta ao organismo, como já foi explicado na visão idealista subjetiva. Em outras palavras, estímulos ambientais gerariam nas pessoas processos mentais que, por sua vez, seriam a causa do comportamento. Esse tipo de behaviorismo ficou conhecido como behaviorismo mediacional, pois tais processos cognitivos mentais mediariam a ação dos estímulos ambientais no organismo, maneira de pensar ainda dualista e mecanicista. Atualmente, chama-se esse tipo de behaviorismo de cognitivismo (Matos, 1993). Assim, não cabe 
dizer que o cognitivismo é uma evolução do behaviorismo radical, uma vez que são bem diferentes.

Com esse paradigma $S \rightarrow R$, a teoria de Watson apresentava grandes problemas para explicar uma série de comportamentos. Então, como Skinner explica comportamentos que não cabem no paradigma estímulo-resposta? Explica-os a partir da noção de comportamento operante.

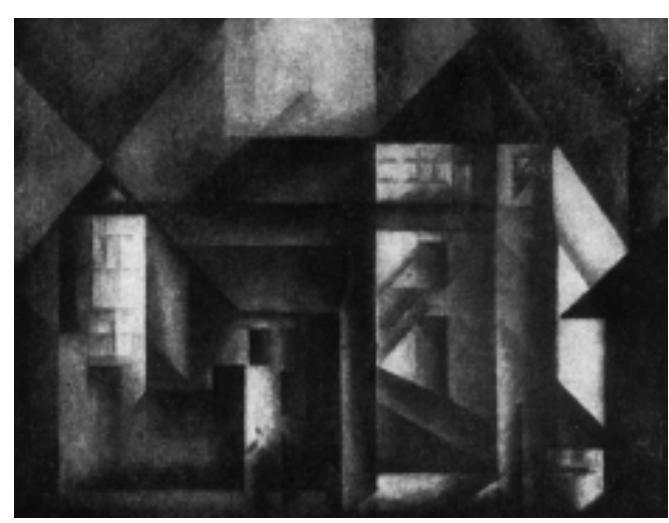

O comportamento operante é aquele cuja causa primeira não está determinada, mas cuja conseqüência pode ser observada. A partir daí, é possível inferir se esse comportamento se repetirá ou não, ou seja, o comportamento é selecionado por suas conseqüências. Fica evidente, desse modo, a saída do paradigma mecanicista $S \rightarrow R$, a partir do qual muitos sofistas, hoje em dia, criticam o behaviorismo radical, e passa-se para o paradigma $R \rightarrow S$, no qual $R$ é o comportamento e $S$ sua conseqüência, que pode ser reforçadora ou punitiva. É assim que o repertório comportamental de uma pessoa é selecionado para o behaviorismo radical. Portanto, fica claro que o behaviorismo radical se distancia da psicologia estímulo-resposta, indo muito além dela, oferecendo respostas a questões do comportamento até então não respondidas.

O paradigma $\mathrm{R} \rightarrow \mathrm{S}$ foi colocado no parágrafo acima para contrastar com o paradigma $S \rightarrow R$ e dar ênfase às conseqüências dos comportamentos, mas, na verdade, o modelo do comportamento operante é uma contingência de três termos $S \rightarrow R \rightarrow S$, onde o primeiro $S$ representa algum acontecimento no ambiente, anterior ao comportamento, e o segundo S, a conseqüência do comportamento. Notem que o primeiro $S$ dessa contingência de três termos é chamado de estímulo discriminativo (representado por SD). Não há nenhuma causação mecanicista do comportamento, pois o que chamamos de estímulo discriminativo é, na verdade, o contexto que estabelece a ocasião para que o organismo se comporte de uma maneira ou de outra, pois, de acordo com sua história ambiental, comportar-se de uma certa maneira em tal contexto produziu conseqüências específicas. Se essas conseqüências foram punitivas, é menos provável que o organismo se comporte de maneira semelhante dado o mesmo contexto, porém se as conseqüências foram reforçadoras, é mais provável que o organismo se comporte de maneira semelhante dado o referido contexto(SD). Esse tipo de operante, no qual se conhecem os estímulos antecedentes, é chamado de operante discriminativo.

Skinner, diferentemente do que muitas pessoas ainda hoje pensam, não rejeitou a introspecção, ele a aceitou, mas não como método, e, sim, enquanto um tipo de comportamento verbal (Matos,1993). Ele a aceitou como forma de observação e obtenção de conhecimento sobre o próprio indivíduo. Afinal de contas, quem melhor do que eu mesmo para saber o que está acontecendo comigo? Quem, além de mim, pode medir ou dizer a dor que sinto no meu braço quebrado? As pessoas podem verificar, através de diversas maneiras, que meu braço está quebrado, e através dos meus comportamentos, como expressão facial, gritos, gemidos etc. podem inferir que eu esteja sentindo dor, podem até inferir a intensidade dessa dor, mas a dor que sinto só eu posso sentir. É, então, deixado de lado o critério da observação consensual do positivismo lógico, adotado por Watson, passando-se para o critério da simples observação, onde o consensual perde a sua importância primordial e a observação realizada por apenas um indivíduo é considerada suficiente. Nesse ponto, é importante perceber que Skinner não foi influenciado pelo positivismo lógico, como muitos pensam, e, sim, pelo positivismo de $\mathrm{E}$. Mach, que foi influenciado pelo pensamento darwinista. Na realidade, não é correto generalizar e dizer que Skinner foi positivista, pois suas relações com o positivismo, de uma forma geral, foram restritas (Tourinho, 2001); enfim, afirmar que Skinner foi positivista, sem realmente demonstrar que características do seu pensamento foram positivistas, é induzir e atribuir características ao pensamento de Skinner que não the pertencem, como, por exemplo, a questão da introspecção mencionada acima. Portanto, é de primordial importância que as pessoas não generalizem, dessa forma, o pensamento de Skinner.

\section{Noção de Ambiente}

Outro motivo de grande confusão para muitas pessoas é a noção de ambiente no behaviorismo radical de Skinner. Assim como Freud deu uma noção bem abrangente para a sexualidade, não se limitando apenas aos órgãos genitais, Skinner fez o 
mesmo em relação ao ambiente. Algumas pessoas só conseguem entender ambiente como ambiente físico estrutural (a casa, a escola etc.), enquanto para Skinner, ambiente vai muito além disso, incluindo aí o ambiente social, onde se encontra todo o tipo de relação pessoal, interpessoal e relação com o próprio ambiente. É por essa razão que, mesmo morando na mesma casa, tendo os mesmos pais, estudando na mesma escola e tendo a mesma carga genética, no caso de gêmeos univitelíneos, se encontram pessoas diferentes, uma vez que seu ambiente físico pode ser o mesmo, mas o ambiente social não. Não obstante, Skinner considera o sujeito como parte do seu ambiente, pois, afinal de contas, o ambiente age sobre o sujeito, modificando-o (modificando o ambiente interno), e o sujeito age sobre o ambiente, também modificando-o (modificando o ambiente externo). Assim, nessa relação, o sujeito constrói sua história de vida. É importante perceber que a história ambiental de reforçamento e punição e a conseqüente seleção dos comportamentos por suas conseqüências, como já foi explicado sobre o comportamento operante, encontram-se incluídos na história de vida do indivíduo.

\section{Críticas \\ Preconceituosas e Infundadas}

Uma das críticas infundadas sobre o behaviorismo radical é que o mesmo não aceitaria nada que tenha a palavra INCONSCIENTE. Na verdade, não se pode aceitar inconsciente enquanto estrutura causadora e controladora do comportamento, enquanto "lugar" onde ficam guardados determinados materiais, memórias sobre certos acontecimentos da vida. Contudo, negar a existência de comportamentos inconscientes seria, no mínimo, insanidade. Comportar-se de maneira inconsciente é, na verdade, não estar consciente do comportamento enquanto todo; é não estar ciente do porquê do comportamento ou de que o comportamento é função, nem das suas conseqüências. É, portanto, não poder descrever as relações funcionais entre contexto e comportamento (Skinner, 1991).

Outro grande problema que o behaviorismo radical enfrenta é a associação inadequada que as pessoas fazem com o nome de certos processos estudados nessa corrente da Psicologia. Fala-se em punição, condicionamento e... pronto! Instantaneamente, as pessoas já estão associando essas palavras ao behaviorismo de forma pejorativa. O behaviorismo radical fala em punição, reforço, condicionamento, extinção enquanto processos que permitem certos comportamentos, e não porque defenda nenhum desses processos em detrimento de outros. Skinner (1998), por exemplo, foi contra a punição, falando dos efeitos maléficos da punição a longo prazo e sugerindo outras maneiras de enfraquecer comportamentos operantes. Em outras palavras, o behaviorismo radical estudou a fundo a punição para poder combater e enfrentar seus efeitos maléficos e, infelizmente, muitos estudantes e até profissionais de Psicologia ainda fazem esse tipo de associação

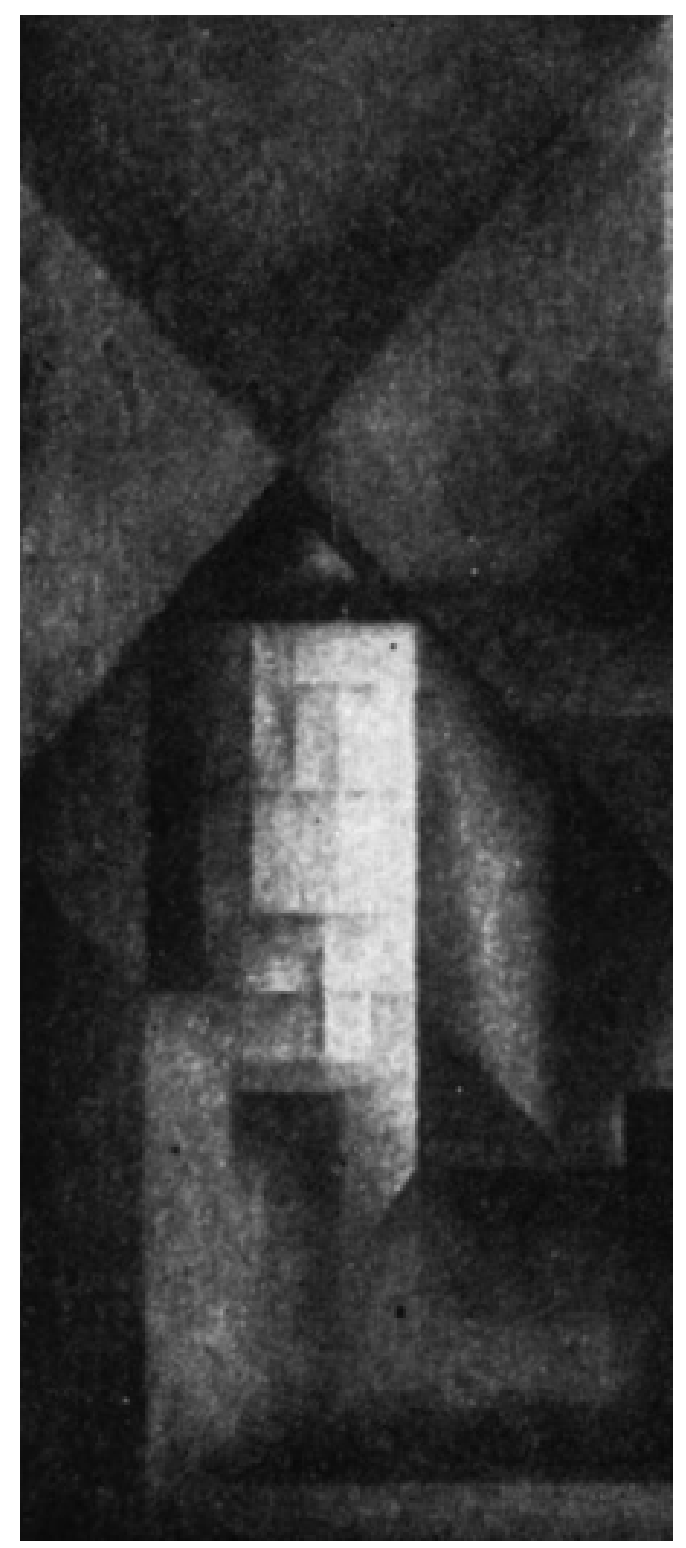

indevida. É também o que acontece com o filme Laranja Mecânica, cujo protagonista passa por um processo de pareamento de estímulos agressivos com mal-estar físico, levando muitos a associarem a prática de tal condicionamento ao behaviorismo. Condicionamento, para o behaviorismo radical, é dar condições para que o sujeito possa se comportar de forma consciente e de acordo com as conseqüências dos seus comportamentos - e não transformar o repertório comportamental de
Uma das críticas

infundadas sobre o behoviorismo radical é que o mesmo não aceitaria nada que tenha a palavra INCONSCIENTE.

Na verdade, não se pode aceitar inconsciente enquanto estrutura causadora $e$ controladora do comportamento, enquanto "lugar" onde ficam guardados determinados materiais, memórias sobre certos acontecimentos da vida. 
uma pessoa em comportamento reflexo, levandoa a se comportar segundo o paradigma $S \rightarrow R$, já mencionado. Para esclarecer melhor esse fato, relato um caso pessoal: discutindo sobre educação infantil durante uma aula, uma colega falou sobre sua experiência em Educação, pois por algum tempo trabalhara com crianças. Ela relatava a maneira como uma certa mãe educava sua criança, quando disse: "ela era ótima, mas era bem rígida, controlava bastante a criança, dava hora para dormir, para acordar, para comer......bem behaviorista mesmo!" Pergunto-me: o que essa atitude tem a ver com o behaviorismo? Só porque usamos o termo controle, quando se discute determinados assuntos, teríamos nós, behavioristas, de ser pessoas muito controladoras? Será que não existem behavioristas permissivos ou gestaltistas, psicanalistas, cognitivistas... controladores?

O homem sempre se comporta de acordo com as contingências. Hora certa para dormir, acordar, tomar banho etc. são contingências que permitem certos comportamentos, mas não ter horário para nada também é um tipo de contingência que permite outros tipos de comportamento, ou seja, não ter horário para nada também é uma forma de controle como qualquer outra; o que muda são apenas as contingências.

\section{Ohomem sempre se comporta de acordo com as contingências. Hora certa para dormir, acordar, tomar banho etc. são contingências que permitem certos comportamentos, mas não ter horário para nada também é um tipo de contingência que permite outros tipos de comportamento, ou seja, não ter horário para nada também é uma forma de controle como qualquer outra; o que muda são apenas as contingências.}


ADDIS, M. E. Aprendendo nas Trincheiras: A Perspectiva de um Estudante sobre o Debate Cognitivo Versus Radical. Informativo ABPMC, no6. Campinas, S.P, 1995.

GEIS, IG STEBBINS, WC, e LUNDIN, R. W. Condicionamento Reflexo e Operante. São Paulo: E.P.U. (Originalmente publicado em 1965 pela Appleton Century-Crofts), 1975.

MARX, M.H., HILLIX, W.A. Sistemas e Teorias em Psicologia. São Paulo, SP: Cultrix, 1973

MATOS, M.A. Behaviorismo Metodológico e suas Relações com o Mentalismo e o Behaviorismo Radical._Em Banaco, R.A. (org.), Sobre Comportamento e Cognição. Vol.1. Santo André, S.P: ARBytes, 1997, pp.54-67.

MICHELETTO, N. Bases Filosóficas do Behaviorismo Radical. Em Banaco, R.A. (org.), Sobre Comportamento e Cognição. Vol.1. Santo André, S.P: ARBytes, 1997, pp. 29-44.

. Há um Lugar para o Ambiente? Em Banaco, R.A. (org.). Sobre Comportamento e Cognição. Vol.1. Santo André, S.P: ARBytes, 1997, pp.257-266.
. Behaviorismo e outros Ismos. Em Kerbauy, R.R e

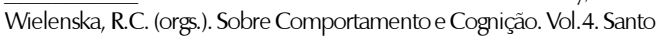
André, S.P: ARBytes, 1999, pp.3-12.

SKINNER, B.F. Questões Recentes na Análise Comportamental. Campinas, SP: Papirus. (Originalmente publicado em 1989 pela Merrill Publishing Company), 1991.

Ciência e Comportamento Humano. São Paulo:

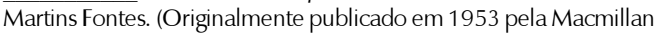
Company), 1998.

TELLES, S.V., CAMILLO, A., PEREIRA, J.A.F. Psicodiagnóstico: Instrumento de Revelação? Anais do I CONPSI, 1988.

TOURINHO, E. Z. A Produção de Conhecimento em Psicologia: A Análise do Comportamento. Trabalho não publicado. Apresentado no $2^{\circ}$ Congresso Norte Nordeste de Psicologia, 2001. Disponível em tourinho@amazon.com.br.Captadonodia 1/06/01.

\section{Referências}

